\title{
Psychometric Properties of the Turkish Version of the University of Virginia Parent Low Blood Sugar Survey
}

\author{
(D) Nesrin Şen Celasinn ${ }^{1}$, (D) Çağrı Çövener Özçelik² , (D) Şükriye Şahin ${ }^{3}$ \\ ${ }^{1}$ Manisa Celal Bayar University Faculty of Health Sciences, Division of Nursing, Department of Pediatric Nursing, Manisa, Turkey \\ ${ }^{2}$ Marmara University Faculty of Health Sciences, Division of Nursing, Department of Pediatric Nursing, Istanbul, Turkey \\ ${ }^{3}$ Marmara University Faculty of Health Sciences, Division of Nursing, Department of Fundemantals of Nursing, Istanbul, Turkey
}

\section{What is already known on this topic?}

It is well known that fear of hypoglycemia causes various problems in achieving metabolic control.

\section{What this study adds?}

This study showed that the Turkish Parent Low Blood Sugar Survey would aid pediatric diabetes nurses in Turkey in the evaluation of the fear of hypoglycemia experienced by parents.

\begin{abstract}
Objective: The aim of this study was to produce and validate a Turkish version of the University of Virginia Parent Low Blood Sugar Survey (P-LBSS). The P-LBSS is used to assess parental fear of their diabetic children's hypoglycemia.

Methods: Linguistic, content and face validity of the translated P-LBSS was tested. Afterwards, explanatory and confirmatory factor analyses were conducted in order to evaluate construct validity.

Results: The sample included 390 parents of type 1 diabetic adolescents aged 12-17 years. Results of the factor analysis showed that the Turkish P-LBSS had 2 subscales (behavior and worry) as in the original. The Cronbach's alpha coefficient of the Turkish version of the total P-LBSS was found to be 0.803 , and the value was 0.865 for the behavior and 0.790 for the worry subscales. Psychometric investigation of the Turkish version of P-LBSS indicated high reliability and good retestability, content and construct validity.

Conclusion: The Turkish P-LBSS is a valid and reliable instrument to measure the fear of hypoglycemia experienced by parents of diabetic adolescents aged between 12-17 years in the Turkish population.
\end{abstract}

Keywords: Type 1 diabetes mellitus, adolescent, validity, reliability, Turkey

\section{Introduction}

Type 1 diabetes mellitus (T1DM) mostly presents during childhood and adolescence $(1,2)$. Although seen in every age group, T1DM usually presents between 7 and 15 years of age (3). Factors such as having a chronic disease, poor adaptation to disease, lifestyle changes, the burden of disease on social life, lowered self-esteem, and fear of complications may negatively affect diabetes management $(4,5)$.

Despite the recent progress in the treatment of T1DM, children and adolescents diagnosed with it are at risk of psychological problems due to the difficulties of diabetes management, such as diet adherence, blood glucose monitoring, insulin administration, physical exercise and self-care (5). Having diabetes brings about changes for the child and his/her family in their daily activities and lifestyle $(5,6,7,8,9,10,11,12)$.

Hypoglycemia is the most commonly seen acute complication in children with T1DM and partially results from intense treatment regimes $(13,14,15,16,17)$. Although transient, hypoglycemia, if untreated, may result in serious morbidity $(16,18,19,20)$. Fear of hypoglycemia negatively 
affects quality of life $(15,21,22,23)$. Patients and families have been reported to deliberately keep blood glucose levels high, despite having been informed of the risks, using strategies such as decreasing insulin doses, overeating, limiting activities and measuring blood glucose very often $(16,19,22,24,25,26)$. It has been reported that parents may measure blood glucose repeatedly at night, increasing both patient and parental stress $(15,17,27,28,29)$.

Diabetes training nurses have a major role to play in educating families and alleviating the fear of hypoglycemia and provide support to affected families $(1,30,31)$. The Virginia Parent Low Blood Sugar Survey (P-LBSS) was developed by Gonder-Frederick et al (16) to assess parental attitudes to childrens' hypoglycemia.

The aim of this study was to assess a Turkish adaptation of the P-LBSS and to evaluate the fear of hypoglycemia experienced by parents of a large cohort of T1DM adolescents.

\section{Methods}

Methodological design was used to determine the validity and reliability of instruments in order to measure constructs used as variables in research (32).

Virginia P-LBSS: The P-LBSS consists of 25 questions in two subscales: the behavior subscale (questions 1-10) and the worry subscale (questions 11-25). Responses are scored on a Likert type scale (never: 0, rarely: 1, sometimes: 2, often: 3, almost always: 4). Total scores range between 0-100 with higher total scores indicating increased fear of hypoglycemia (16). The Cronbach's alpha reliability coefficients of the original total scale, the behavior subscale, and the worry subscale were found to be $0.89,0.76$ and 0.91 , respectively, indicating good reliability.

The questionnaire was translated into Turkish by two competent English teachers. In order to test content validity, the scale was assessed for comprehensibility by 18 experts. The experts scored each item on a scale of 1 to 4 in accordance with the Davis technique (1992) (33). Finally, the scale was completed by 15 adolescents to evaluate scale legibility. Small corrections were made to achieve face validity. In addition, a Parent Identification Form was prepared in line with the literature $(1,14,30)$ which consisted of 15 items with seven open ended and eight closed questions about sociodemographic characteristics.

Parents of adolescents aged between 12-17 years with T1DM were invited to participate in this study. Subjects were recruited from five hospitals, three in İstanbul and two in
İzmir. Since adaptation to a chronic disease takes up to one year, parents of adolescents with a diabetes duration of one year or more, who regularly received routine three monthly follow-up care, were invited to participate. Sample size for questionnaire adaption studies should be between twice and ten times the number of questions included $(34,35,36)$. The P-LBSS used in this study has 25 items and the aim was to recruit at least 250 families.

The data were collected between March and June 2016. Completion of the test took 15 to 20 minutes. For test retest reliability, the scale was repeated by the same parents three weeks later.

\section{Ethical Considerations}

Ethical board permission was taken from the Marmara University Health Sciences Institute Ethical Board (IRB no: 26.10.2015-14). Written permission from the institutions where the study would be conducted were obtained. Prior to data collection, the participants were informed about the study. Parents who agreed to participate in the study gave written informed consent.

\section{Statistical Analysis}

Number Cruncher Statistical System 2007 (Kaysville, Utah, USA) was used for statistical analyses. The expert views on the content validity of the scale were evaluated using the content validity index (CVI) (36). In order to evaluate structure validity, confirmatory and explanatory factor analyses were performed. In the reliability analysis, the Cronbach's alpha values and item-total score correlation coefficients were calculated. In test-retest reliability, the Intraclass Correlation Coefficient (ICC) was calculated. Descriptive statistical analyses [mean, standard deviation (SD), percentages] were also used. Data was evaluated at a $95 \%$ confidence interval. Significance level was set at $p<0.05$.

\section{Results}

Mean age of the mothers and fathers was $42.44 \pm 6.44$ (range 29-56) and $46.37 \pm 6.51$ (28-56) years respectively. Mean \pm SD time since diagnosis was $5.96 \pm 3.47$ (range 1-17) years. Mean hemoglobin A1c value was found to be $8.96 \pm 1.82 \%$. Expert assessment of the questionnaire by CVI scoring gave a maximum value of 1.00 .

Construct validity: Explanatory and confirmatory factor analyses were performed to test construct validity.

Explanatory factor analysis: The Kaiser-Meyer-Olkin (KMO) coefficient was found to be 0.881 . Thus, it was shown that the sample size was sufficient for factor analysis. The Bartlett's sphericity test was found to be significant 
$(p<0.05)$, showing that the data set had multivariate normality $(37,38)$. The result of the Bartlett's sphericity test in this study was found to be $\chi^{2}=3630, d f=325, p=0.001$. A Varimax rotation was used and the scale was found to have two factors as in the original scale, factor 1 being the behavior subscale and factor 2 the worry subscale. Factor loadings in factor 1 were found to range between 0.315 and 0.879 and in factor 2 between 0.304 and 0.638 (Table 1). The two-factor structure explained $39.1 \%$ of the total variance. Factor loadings were acceptable (Table 1).

Confirmatory factor analysis: Confirmatory factor analysis confirms the factors determined in explanatory factor analysis (39). For the structural validity of a scale to be confirmed, the "Goodness of fit statistics", which can be obtained via confirmatory factor analysis, should be at acceptable levels. In the current study, the factor model fit the data $(p<0.001)$ and the Root Mean Square Error of Approximation (RMSEA) was 0.086 (Figure 1). The $\chi^{2} / \mathrm{df}$ index was found to be 3.88 .

Reliability: Item-total correlations were found to vary between 0.019 and 0.595 (Table 1). The Cronbach's alpha coefficients of the scale are given in Table 2 . The test-retest reliability results are given in Table 3. According to the results of the ICC analysis, the level of consistency between

\begin{tabular}{|c|c|c|c|c|}
\hline \multirow{2}{*}{$\begin{array}{l}\text { Item } \\
\text { no }\end{array}$} & \multirow[t]{2}{*}{ Items } & \multicolumn{2}{|c|}{ Factor loads } & \multirow{2}{*}{$\begin{array}{l}\text { Item to total } \\
\text { correlation }\end{array}$} \\
\hline & & $\begin{array}{l}\text { Factor } 1 \\
\text { (behavior) }\end{array}$ & $\begin{array}{l}\text { Factor } 2 \\
\text { (worry) }\end{array}$ & \\
\hline 1 & Have my child eat large snacks at bedtime & 0.674 & - & 0.293 \\
\hline 2 & Avoid having my child being alone when his/her sugar is likely to be low & 0.315 & - & 0.312 \\
\hline 3 & Allow my child's blood sugar to be a little high to be on the safe side & 0.768 & - & 0.477 \\
\hline 4 & Keep my child's sugar higher when he/she will be alone for a while & 0.841 & - & 0.522 \\
\hline 5 & $\begin{array}{l}\text { Have my child eat something as soon as he/she feels the first sign of low blood } \\
\text { sugar }\end{array}$ & 0.348 & - & 0.204 \\
\hline 6 & Reduce my child's insulin when I think his/her sugar is too low & 0.745 & - & 0.466 \\
\hline 7 & $\begin{array}{l}\text { Keep my child's blood sugar higher when he/she plans to be away from me for a } \\
\text { while }\end{array}$ & 0.879 & - & 0.537 \\
\hline 8 & Have my child carry fast-acting sugar & 0.550 & - & 0.362 \\
\hline 9 & Have my child avoid a lot of exercise when I think his/her sugar is low & 0.617 & - & 0.396 \\
\hline 10 & Check my child's sugar often when he/she plans to go on an outing & 0.699 & - & 0.352 \\
\hline 11 & $\begin{array}{l}\text { Child will not be able to recognize that he/she is having symptoms of } \\
\text { hypoglycemia }\end{array}$ & - & 0.358 & 0.289 \\
\hline 12 & Child is not carrying food, fruit, or juice with him/her & - & 0.304 & 0.019 \\
\hline 13 & Child feeling dizzy or passing out in public & - & 0.543 & 0.391 \\
\hline 14 & Child having a low blood sugar while asleep & - & 0.565 & 0.362 \\
\hline 15 & Child embarrassing self or friends/family in a social situation & - & 0.434 & 0.396 \\
\hline 16 & Child having a low while alone & - & 0.595 & 0.417 \\
\hline 17 & Child appearing to be "stupid" or clumsy & - & 0.454 & 0.357 \\
\hline 18 & Child losing control of behaviour due to low blood sugar & - & 0.482 & 0.501 \\
\hline 19 & No one being around to help my child during a low & & 0.587 & 0.322 \\
\hline 20 & Child making a mistake or having an accident at school & - & 0.638 & 0.370 \\
\hline 21 & $\begin{array}{l}\text { Child getting a bad evaluation at school because of something that happens when } \\
\text { his/her sugar is low }\end{array}$ & - & 0.464 & 0.303 \\
\hline 22 & Child having seizures or convulsions & - & 0.617 & 0.052 \\
\hline 23 & $\begin{array}{l}\text { Child developing long term complications from frequent } \\
\text { low blood sugar }\end{array}$ & - & 0.599 & 0.220 \\
\hline 24 & Child feeling light-headed or faint & - & 0.597 & 0.595 \\
\hline 25 & Child having a low & - & 0.636 & 0.335 \\
\hline
\end{tabular}


Table 2. Internal consistency of University of Virginia Parent Low Blood Sugar Survey

\begin{tabular}{|c|c|c|c|c|c|}
\hline & \multicolumn{2}{|c|}{$\begin{array}{l}\text { Number of } \\
\text { items }\end{array}$} & \multicolumn{3}{|c|}{$\begin{array}{l}\text { Internal consistency } \\
\text { (Cronbach's alpha) }\end{array}$} \\
\hline \multicolumn{2}{|l|}{ Behaviour } & 10 & \multicolumn{3}{|l|}{0.865} \\
\hline \multicolumn{2}{|l|}{ Worry } & 15 & \multicolumn{3}{|l|}{0.790} \\
\hline \multicolumn{2}{|l|}{ Total scale } & 25 & \multicolumn{3}{|l|}{0.803} \\
\hline \multicolumn{6}{|c|}{$\begin{array}{l}\text { Table } 3 \text {. Test-retest reliability of University of Virginia } \\
\text { Parent Low Blood Sugar Survey }\end{array}$} \\
\hline \multirow[t]{2}{*}{$\mathrm{n}=79$} & $\begin{array}{l}\text { First } \\
\text { measurement }\end{array}$ & \multicolumn{2}{|c|}{$\begin{array}{l}\text { Second } \\
\text { measurement }\end{array}$} & \multirow[t]{2}{*}{$\begin{array}{l}\text { ICC } \\
(\% 95 \mathrm{CI})\end{array}$} & \multirow[t]{2}{*}{$\mathrm{p}$} \\
\hline & Mean \pm SD & \multicolumn{2}{|c|}{ Mean \pm SD } & & \\
\hline Behaviour & $2.72 \pm 0.85$ & \multicolumn{2}{|c|}{$2.75 \pm 0.84$} & 0.924 & 0.000 \\
\hline Worry & $2.18 \pm 0.74$ & \multicolumn{2}{|c|}{$2.24 \pm 0.79$} & 0.749 & 0.000 \\
\hline Total scale & $2.39 \pm 0.59$ & \multicolumn{2}{|c|}{$2.44 \pm 0.63$} & 0.825 & 0.000 \\
\hline \multicolumn{6}{|l|}{$p<0.001$} \\
\hline \multicolumn{6}{|c|}{$\begin{array}{l}\text { CI: confidence interval, ICC: intraclass correlation coefficient, SD: standard } \\
\text { deviation }\end{array}$} \\
\hline
\end{tabular}

the first and last measurements was $92.4 \%$ for the behavior subscale, $74.9 \%$ for the worry subscale and $82.5 \%$ for the total scale.

\section{Discussion}

The main characteristics sought in a good instrument are reliability and validity (32). In the current study, the psychometric properties of the Turkish version of the P-LBSS were examined in detail.

Content validity represents the universe of content or the domain of given constructs $(40,41)$. A CVI value above 0.80 indicates good content validity (36). In the present study, the CVI was found to be 1.00 indicating excellent content validity.

In the current study, the KMO and the Bartlett's sphericity test were used to evaluate sample size adequacy. KMO may range from 0 to 1 , with higher values indicating appropriate sample size $(34,38)$. In the literature, KMO values between 0.80 and 0.89 reflect a "very good" sample size (35).

In this study, the KMO was found to be 0.881 , indicating sample size adequacy. The Bartlett's sphericity test was used to test the hypothesis that correlation matrices were similar, and this hypothesis was rejected at a value of $p=0.001$. The results of the Bartlett's test being $p<0.01$ showed that measurement was not affected by the sample size and that the sample size was adequate for factor analysis.

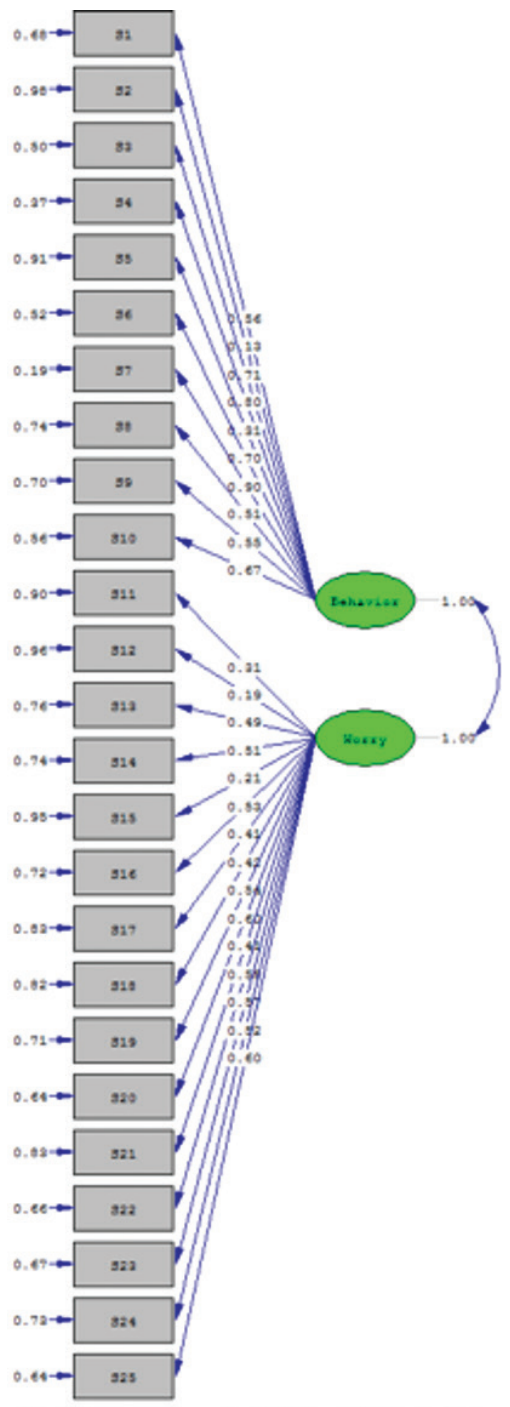

Chi-9quare $=1063.54, d f=274, p-v_{a l u e}=0.00000, \quad R M g E A=0.086$

Figure 1. Path diagram of confirmatory factor analysis for University of Virginia Parent Low Blood Sugar Survey

Construct validity was tested using explanatory and confirmatory factor analysis. The factor analytical approach is a procedure that provides information about the extent to which a set of items measure the same underlying construct $(40,41)$.

The Varimax rotation method showed that the two-factor structure explained $39.1 \%$ of the total variation. Higher variance rates indicate a stronger factor structure.

Factor loadings of items in factor 1 ranged between 0.315 and 0.879 , and in factor 2 between 0.304 and 0.638 . Factor loadings should be a minimum of 0.30 in scale development and adaptation to discriminate between the characteristics to be measured (38), thus adequate discrimination was present. In the interpretation of goodness of fit indices in confirmatory factor analysis, the RMSEA fit index is used 
to assess goodness of fit indices in confirmatory factor testing with $0<$ RMSEA $<0.05$ showing good fit, while $0.05 \leq$ RMSEA $\leq 0.10$ shows acceptable fit $(38,42)$. The RMSEA value of our instrument was 0.086 indicating acceptable fit. Similarly, a $\chi^{2} / \mathrm{df}$ fit index of $\leq 3$ shows perfect fit and $\leq 5$ shows good fit (43). The $\chi^{2} / \mathrm{df}$ value for our questionnaire was 3.88 indicating good fit.

Reliability of an instrument refers to the extent to which the instrument yields consistent results on repeated measures (40). There are five major techniques for reliability testing. These techniques include test-retest reliability, parallel or alternate forms, item-total correlation, split-half reliability, Kuder-Richardson-20, Cronbach's alpha, and inter-rater reliability (40). In the current study, the Cronbach's alpha coefficient, item-total correlations and test-retest reliability were used. In scale development and adaptation, scales with Cronbach's alpha values at and above 0.70 are accepted as reliable (38). Accordingly, the Cronbach's alpha reliability coefficients of the total scale and the behavior and worry subscales were found to be acceptable (Table 2). These values showed that the scale is a reliable instrument and parallel results were obtained with the original scale.

Item-total correlations show the reliability of each item in a scale (36). An item total score correlation of 0.30 and above shows that the items are adequate for measuring the desired characteristic and that the items are consistent with the total scale $(38,39)$. In the present study, the item-total correlations ranged from 0.019 to 0.595 with four questions giving values below 0.30 . However, since the factor structure was tested using confirmatory factor analysis, and since the Cronbach's alpha coefficient of the scale was above 0.70 , the original structure of the scale was maintained. Thus, the four items were not removed from the scale.

Test-retest reliability is used for evaluating the consistency of the scale over time, with values above 0.70 indicating good retest reliability (38). The correlation values obtained in this study indicated perfect correlation and demonstrated the consistency of scale scores over time (Table 3).

The usability of the scale should also be tested in parents of adolescents with a diabetes duration of less than one year and adolescents with co-morbid disorders such as celiac disease or hypothyroidism.

\section{Conclusion}

The Turkish version of the P-LBSS had high reliability and good content and construct validity. The Turkish P-LBSS is a valid and reliable instrument to measure the fear of hypoglycemia experienced by parents of T1DM adolescents in the Turkish population. Additionally, the P-LBSS, which is easy for pediatric diabetes nurses to use, can help in evaluating parental fear of childrens' hypoglycemia. Thus, appropriate psychological help could be provided. Use of this questionnaire may have the effect of improving the quality of adolescent diabetic nursing care in Turkey.

\section{Acknowledgments}

We thank all the parents and families for participating in the study. We also thank Prof. Dr. Sevin Altınkaynak, Prof. Dr. Güler Cimete, Prof. Dr. Hicran Çavuşoğlu, Prof. Dr. Nursan Çınar, Prof. Dr. Firdevs Erdemir, Prof. Dr. Ayşe Ferda Ocakçi, Prof. Dr. Candan Öztürk, Prof. Dr. Suzan Yıldız, Prof. Dr. Rana Yiğit, Assoc. Prof. Dr. Gülçin Bozkurt, Assoc. Prof. Dr. Rabia Ekti Genç, Assoc. Prof. Dr. Duygu Gözen, Assoc. Prof. Dr. Selmin Şenol, Assoc. Prof. Dr. Türkan Turan, Assist. Prof. Dr. Özlem Avci, Lecturer Dijle Özer, Dr. Gülten Okuroğlu, Msn. Eda Aktaş for their expert opinions.

\section{Ethics}

Ethics Committee Approval: Ethical board permission was taken from the Marmara University Health Sciences Institute Ethical Board (IRB no: 26.10.2015-14).

Informed Consent: Parents who agreed to participate in the study gave written informed consent.

Peer-review: Externally peer-reviewed.

\section{Authorship Contributions}

Design: Nesrin Şen Celasin, Çağrı Çövener Özçelik, Data Collection or Processing: Nesrin Şen Celasin, Şükriye Şahin, Analysis or Interpretation: Çağrı Çövener Özçelik, Literature Search: Nesrin Şen Celasin, Çağrı Çövener Özçelik, Writing: Nesrin Şen Celasin, Çağrı Çövener Özçelik.

Financial Disclosure: The authors declared that this study received no financial support.

\section{References}

1. Bilous R, Donelly R. Diabetes Handbook, Translation: In: Dinçdağ N (ed). 4th, Istanbul, Istanbul Medical Bookstore, 2013;229.

2. International Diabetes Federation (IDF). Diabetes Atlas, 6th ed. Brussels, 2013.

3. Çövener Ç, Ocakçı AF. Type 1 Diabetes Management: Example of a Nursing Model. HEAD 2013;10:30-37.

4. Szydlo D, Van Wattum PJ, Woolston J. Psychological aspects of diabetes mellitus. Child Adolesc Psychiatr Clin N Am 2003;12:439-458.

5. Fettahoğlu Ç, Koparan C, Özatalay E, Türkkahraman D. The Psychological Difficulties in Children and Adolescents with Insulin Dependent Diabetes Mellitus. Psychiatry in Turkey 2007;9:32-36.

6. Kovacs M, Goldston D, Obrosky DS, Bonar LK. Psychiatric disorders in youths with IDDM: rates and risk factors. Diabetes Care 1997;20:3644. 
7. Grey M, Whittemore R, Taborlane W. Depression in type 1 diabetes in children: Naturel history and correlates. J Psychosom Res 2002;53:907-911.

8. Blanz BJ, Rensch-Riemann BS, Fritz-Sigmund DI, Schmidt MH. IDDM is a risk factor for adolescent psychiatric disorders. Diabetes Care 1993;16:1579-1587.

9. Kovacs M, Obrosky DS, Goldston D, Drash A. Major depressive disorders in youths with IDDM. A controlled prospective study of course and outcome. Diabetes Care 1997;20:45-51.

10. Nakazato M, Kodama K, Miyamoto S, Sato M, Sato T. Psychiatric disorders in juvenile patients with insulin-dependent diabetes mellitus. Diabetes Res Clin Pract 2000;48:177-183.

11. Grey M, Cameron ME, Lipman TH, Thurber FW. Psychosocial status of children with diabetes in the first 2 years after diagnosis. Diabetes Care 1995;18:1330-1336.

12. Kovacs M, Mukerji P, Iyengar S, Drash A. Psychiatric disorder and metabolic control among youths with IDDM. A longitudinal study. Diabetes Care 1996;19:318-323.

13. Barnard K, Thomas S, Royle P, Noyes K, Waugh N. Fear of hypoglycaemia in parents of young children with type 1 diabetes: a systematic review. BMC Pediatr 2010;10:50.

14. Gonder-Frederick L, Nyer M, Shepard JA, Vajda K, Clarke W. Assessing fear of hypoglycemia in children with Type 1 diabetes and their parents. Diabetes Manag (Lond) 2011;1:627-639.

15. Shepard JA, Vajda K, Nyer M, Clarke W, Gonder-Frederick L. Understanding the Construct of Fear of Hypoglycemia in Pediatric Type 1 Diabetes. J Pediatr Psychol 2014;39:1115-1125. Epub 2014 Sep 11

16. Gonder-Frederick LA, Fisher CD, Ritterband LM, Cox DJ, Hou L, DasGupta AA, Clarke WL. Predictors of fear of hypoglycemia in adolescents with type 1 diabetes and their parents. Pediatr Diabetes 2006; 7:215-222

17. Patton SR, Dolan LM, Henry R, Powers SW. Fear of Hypoglycemia in Parents of Young Children with Type 1 Diabetes Mellitus. J Clin Psychol Med Settings 2008;15:252-259. Epub 2008 Jul 26

18. McCrimmon RJ, Gold AE, Deary IJ, Kelnar CJ, Frier BM. Symptoms of hypoglycemia in children with IDDM. Diabetes Care 1995;18:858-861.

19. Clarke WL, Gonder-Frederick A, Snyder AL, Cox DJ. Maternal fear of hypoglycemia in their children with insulin dependent diabetes mellitus. J Pediatr Endocrinol Metab 1998;11 (Suppl 1):189-194.

20. Kamps JL, Roberts MC, Varela RE. Development of a New Fear of Hypoglycemia Scale: Preliminary Result. J Pediatric Psychol 2005;30:287-291. Epub 2005 Feb 23

21. Cox DJ, Irvine A, Gonder-Frederick L, Nowacek G, Butterfield J. Fear of hypoglycemia: quantification, validation, and utilization. Diabetes Care 1987;10:617-621.

22. Irvin A, Cox D, Gonder-Frederick L. The Fear of Hypoglycaemia Scale. In: Bradley C (ed). Handbook of Psychology and Diabetes: A Guide to Psychological Measurement in Diabetes Research and Practice. Amsterdam, Harwood Academic Publishers, 1994;133-155.

23. Clarke W, Jones T, Rewers A, Dunger D, Klingensmith GJ. Assessment and management of hypoglycemia in children and adolescents with diabetes. Pediatric Diabetes 2009;10(Suppl 12):134-145.

24. Frier BM. How hypoglycaemia can affect the life of a person with diabetes. Diabetes Metab Res Rev 2008;24:87-92.

25. Shi L, Shao H, Zhao Y, Thomas NA. Is hypoglycemia fear independently associated with health-related quality of life? Health Qua Life Outcomes 2014;12:167.
26. Görpe U. Psychosocial Issues in Diabetes Mellitus Disease. Symposium Series of Frequent Psychiatric Diseases in Turkey 2008;62:259-262.

27. Haugstvedt A, Wentzel-Larsen T, Rokne B, Graue M. Perceived family burden and emotional distress: Similarities and differences between mothers and fathers of children with type 1 diabetes in a populationbased study. Pediatr Diabetes 2011;12:107-114.

28. Monaghan MC, Hilliard ME, Cogen FR, Streisand R. Nighttime caregiving behaviors among parents of young children with type 1 diabetes: Associations with illness characteristics and parent functioning. Fam Syst Health 2009;27:28-38.

29. Streisand R, Swift E, Wickmark T, Chen R, Holmes CS. Pediatric parenting stress among parents of children with type 1 diabetes: The role of self-efficacy, responsibility, and fear. J Pediatr Psychol 2005;30:513-521. Epub 2005 Mar 3

30. Celasin NS, Başbakkal Z, Demir G, Gökşen D, Darcan Ş. The effect of consulting via internet on fear of hypoglycemia and metabolic control in adolescents with type 1 diabetes: P/109/FRI. Pediatric and Adolescent Diabetes (ISPAD), 27-30 October 2010, Buenos Aires, Argentina. Pediatric Diabetes 2010;11 (Suppl 14):75.

31. Diyabet Hemşireliği,http://www.tdhd.org/pdf/30_03_15_DIYABET_ HEMSIRELIGI.pdf

32. Emiroğlu O. Experimental Designs. In: Erefe I (ed). Research Principles, Processes and Methods in Nursing. Istanbul, Odak Offset, 2013;91124.

33. Davis LL. Instrument review: Getting the most from a panel of experts. Applied Nursing Research 1992;5:194-197.

34. Öksüz E, Malhan S. Quality of Life Dependent on Health-The Kalitemetry. Başkent University, Ankara, 2005;60-120.

35. Karagöz Y. SPSS 21.1 Applied Biostatistics. Ankara, Nobel Academic Publishing, 2014;50-160.

36. Esin NM. Research in Nursing: Process, Application and Critical. In: Erdoğan S, Nahcivan N, Esin N (eds). Istanbul, Nobel Medical Bookstore, 2014;217-226

37. Büyüköztürk Ş. Data Analysis Handbook for Social Sciences. Ankara, Pegem Academy Publishing, 2014;179-194.

38. Haber J, LoBiondo-Wood G. Reliability and Validity. In: LoBiondo-Wood G, Haber J. (eds). Nursing Research Methods and critical Appraisal for Evidence-Based Practice, 6th ed. Missouri, Mosby Elsevier, 2006;335356.

39. Wood MJ, Ross-Kerr JC. Reliability and Validity of Measurement in Basic Steps in Planning Nursing Research. 6th ed. Boston, MA: Jones and Barlett Publishers, 2006;195-221.

40. Seçer İ. Psychological test development and adaptation process, SPSS and LISREL applications. Ankara, An1 Publishing, 2015;77-99.

41. Çelik ER, Yılmaz V. Structural equation modeling with LISREL 9.1. Basic concepts, applications, programming. 2nd ed. Ankara, An1 Publishing, 2013;43-51.

42. Çokluk Ö, Şekercioğlu G, Büyüköztürk Ş. Multivariate Statistical SPSS and LISREL Applications For Social Sciences. 2nd ed. Ankara, Pegem Academy, 2012;271.

43. Şencan H. Reliability and Validity in Social and Behavioral Measurements. Ankara, Seçkin Publishing, 2005;89-100. 